\title{
Effects of impact velocity on the dynamic fragmentation of rigid- brittle projectiles and ceramic composite armors
}

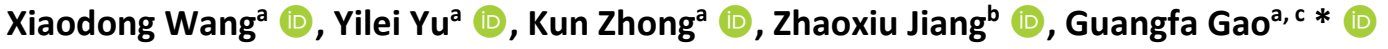 \\ a School of Mechanical Engineering, Nanjing University of Science and Technology, Nanjing, Jiangsu 210094, China. \\ E-mails:wxd202@njust.edu.cn, yileiyu@njust.edu.cn, njzhongkun@163.com,gfgao@ustc.edu.cn \\ ${ }^{b}$ MOE Key Laboratory of Impact and Safety Engineering, Ningbo University, Ningbo, Zhejiang 315211, China. \\ E-mail: jiangzhaoxiu@njust.edu.cn \\ ' State Key Laboratory of Explosion Science and Technology, Beijing Institute of Technology, Beijing 100081, China. \\ E-mail: gfgao@ustc.edu.cn \\ * Corresponding author
}

https://doi.org/10.1590/1679-78256701

\begin{abstract}
The silicon carbide $(\mathrm{SiC}) /$ metal composite armors with the composite cover on the front of the SiC plate were impacted by $12.7 \mathrm{~mm}$ armor piercing incendiary (API) projectiles at velocities from $412.6 \mathrm{~m} / \mathrm{s}$ to $802.2 \mathrm{~m} / \mathrm{s}$. The resulting projectile core and ceramic fragments were collected and then screened through a range of standard sieving screens. The mass distributions of fragments produced by projectile and ceramic impacting each other were obtained. The failure mechanism of the rigid-brittle core of $12.7 \mathrm{~mm}$ API projectile after impacting $\mathrm{SiC} /$ metal composite armor was studied by examination of the failed core. The results show that the cumulative mass of core and ceramic fragments follow the Schuhmann distribution law. With the increase of impact velocity, the mass proportion of small core fragments increases, while for ceramic fragments, the mass proportion of fragments in different fractions does not change. The failure mechanism of the large equivalent diameter fragment ( $>8 \mathrm{~mm}$ ) is tensile brittle fracture mainly. In contrast, the local plastic shear fracture exists on the fragments with an equivalent diameter of less than $2 \mathrm{~mm}$.
\end{abstract}

\section{Keywords}

Rigid-brittle projectile; Fragmentation; Statistical analy sis; Composite armor; Ballistic tests

\section{Graphical abstract}

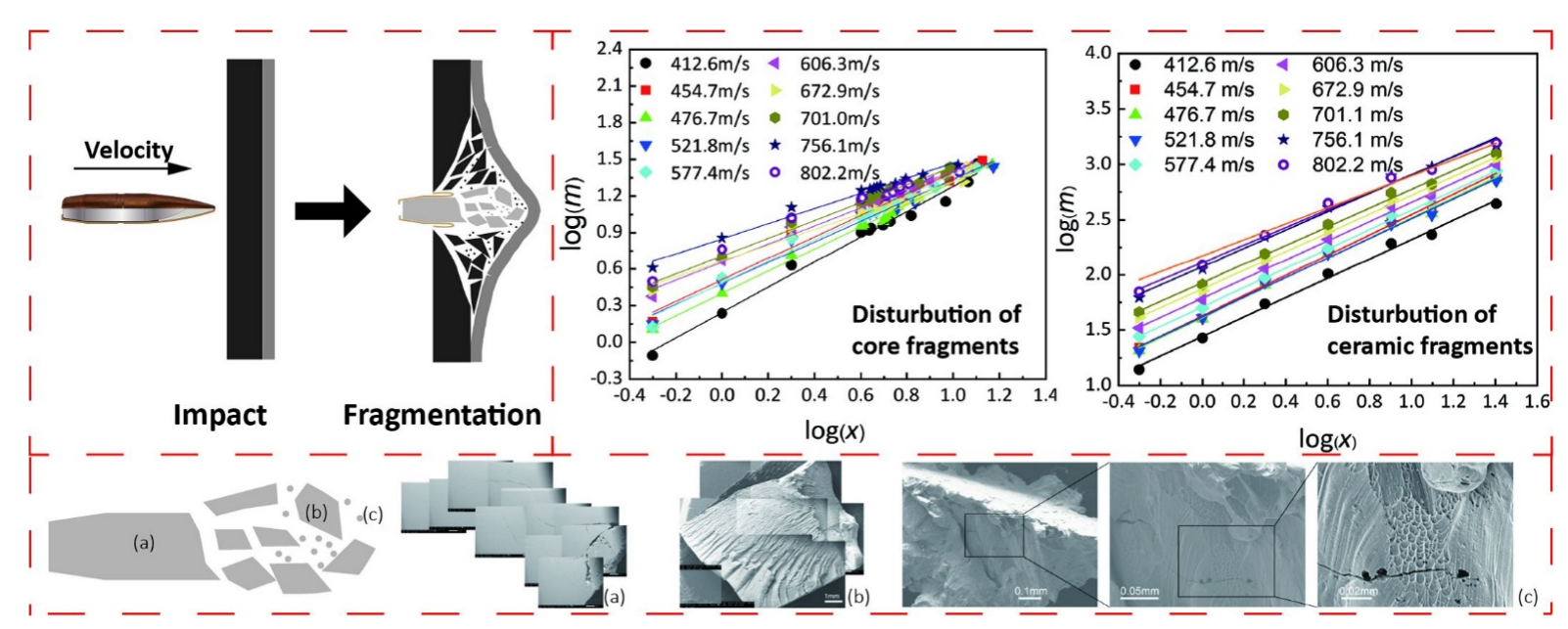




\section{INTRODUCTION}

Ceramic/metal composite target (Madhu et al., 2005; Savio et al., 2017; Wang et al., 2013) has become one of the main protective structures under the lightweight requirements of military equipment such as aircraft and armored vehicles. The ceramic/metal armor is composed of a ceramic faceplate, a metal backplate, and the adhesive layer between them. This lightweight armor combines the advantages of the hardness of ceramics and the toughness of metal. The ceramics plate can erode and fragment an impacting projectile effectively in the penetration process, thereby reducing the penetration ability of the projectile. The ceramic cone formed by the broken ceramic face plate absorbs the kinetic energy of the projectile, transfers the impact load, and changes the failure mode of the backplate.

The API projectile generally comprises a hard-steel core, a steel or copper jacket, a low-mass lead can, and incendiary material. The major penetrator is the hard-steel core, which shows two completely different characteristics when penetrating metal targets and ceramic composite armors. When penetrating metal targets, such as aluminum alloy (Børvik et al., 2010; Demir et al., 2008; Holmen et al., 2013), titanium alloy (Jung et al., 2020; Liu et al., 2015; Sukumar et al., 2013) and steel (Demir et al., 2008; Holmen et al., 2017), the hard-steel core has no deformation and erosion. Even when it breaks due to asymmetric stress, the core head remains intact (Ali et al., 2017; Chocron, 2001; Kılıç et al., 2014), making it possible to equate the projectile core as a rigid body when studying these problems. When penetrating ceramic composite armors (Madhu et al., 2005; Rahbek and Johnsen, 2019; Savio et al., 2011; Savio et al., 2015), the hard-steel core will break into fragments of different sizes, showing the characteristics of brittle fracture. So, it is particularly important to study the fragmentation characteristics of the rigid-brittle core when it penetrates ceramic composite armor.

Studying the fragmentation characteristics of the projectile core and ceramic plate is important to quantify and predict the erosion and fragmentation of ones. This can help us to understand the interaction mechanism of the projectile and the target and subsequent penetration ability. The research on the fragmentation characteristics of the projectile in the process of projectile impacting target at present, focuses mainly on the microscopic fracture mechanism of the core and the macroscopic fragment size. The research on the micro-fracture mechanism of the rigid-brittle core includes: Savio (Savio et al., 2015) studied the fragmentation mechanism of $7.62 \mathrm{~mm}$ armor piercing projectile after penetrating $\mathrm{SiC}$ ceramics from the micro perspective. Di Benedetto (Di Benedetto et al., 2018) studied the macro and micro failure mechanism of various materials' cores, including tool steel, after penetrating the targets. Hogan (Hogan et al., 2017) using scanning electron microscopy (SEM) found the failure mechanism of blocky fragments and shard fragments and studied the relationship between the directions of fracture surfaces and impact direction. Savio (Savio et al., 2011) carried out a depth of penetration (DOP) experiment, counted the particle size distribution of ceramic fragments produced by various thickness ceramic plates. In the experiment, the interaction time between projectile and ceramic increases with the increase of ceramic thickness, resulting in more and finer ceramic powder. The material of the core of the $12.7 \mathrm{~mm}$ API projectile is different from those in the above references, although some of their properties are similar. Whether there are differences in fracture and failure characteristics needs to be further studied. The same is true for ceramics.

In the process of $12.7 \mathrm{~mm}$ API projectile impacting ceramic/metal composite target, the force state of the projectile and target is complex. Many factors affect the fragmentation of the core and ceramic plate, among them, the impact velocity is one of the important ones. To study the effect of impact velocity on the size distribution of core and ceramic fragments, a series of experiments of $12.7 \mathrm{~mm} \mathrm{API} \mathrm{projectiles} \mathrm{penetrating} \mathrm{SiC} /$ metal composite targets were carried out in this paper. The projectile's velocity ranged from $412 \mathrm{~m} / \mathrm{s}$ to $802 \mathrm{~m} / \mathrm{s}$. The failure mechanisms of fragments in different fractions of the core were analyzed using SEM. The resulting core and ceramic fragments were collected and screened through a range of standard sieving screens. The cumulative mass distributions of core and ceramic fragments after impact at a series of velocities were obtained. A combination of statistical distribution and microscopic observation were used to study the fragmentation characteristics in this paper. This will provide data reference for quantifying the fragmentation energy of cores and ceramics.

\section{EXPERIMENTS}

\subsection{Projectiles and targets}

The projectiles used for testing are standard $12.7 \mathrm{~mm}$ API projectiles, shown in Figure 1 . The projectile is composed of a hard-steel core, copper-plated steel jacket, lead can, and incendiary material in the front spaces between the jacket and the steel core. The average mass of the projectiles used in the experiments was $48.2 \pm 0.8 \mathrm{~g}$. The rigid-brittle core is a high-strength steel cylinder with an ogival nose, a diameter of $10.8 \mathrm{~mm}$, and a mass of $30.1 \mathrm{~g}$. 


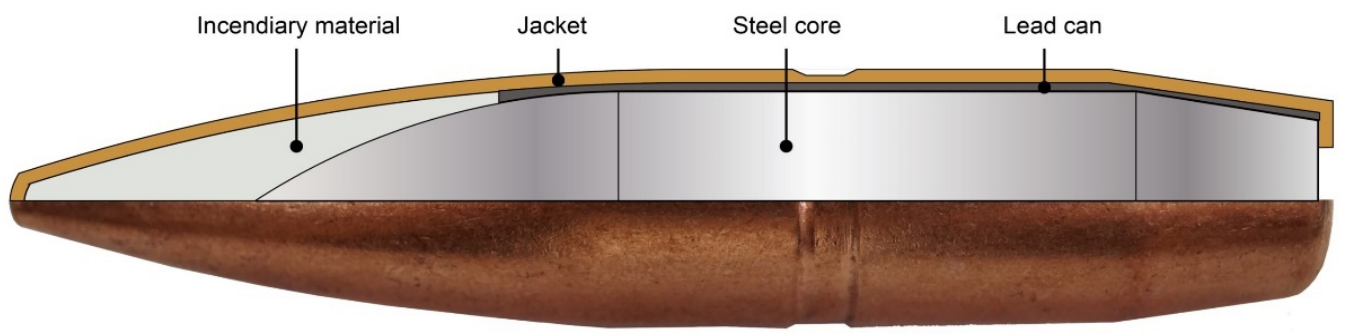

Figure 1: Structure of $12.7 \mathrm{~mm}$ API projectile

The armor piercing core is a kind of high-carbon steel with special heat treatment, and its microhardness measured at their various locations was found to be 764 789HV0.5. This material shows obvious tension-compression asymmetry, as shown in Figure 2. In addition, the material had obvious tensile brittleness, and the quasi-static tensile fracture strain was in the range of $1.0 \sim 1.5 \%$. But it has obvious plastic deformation under uniaxial compression conditions. The above researches show that the core material of $12.7 \mathrm{~mm}$ API projectile is a high-strength metal with brittleness in tension but plasticity in compression. The cores of $7.62 \mathrm{~mm} \mathrm{API} \mathrm{projectiles} \mathrm{have} \mathrm{been} \mathrm{found} \mathrm{to} \mathrm{have} \mathrm{similar} \mathrm{material} \mathrm{properties,}$ although these projectiles may come from different countries (Chocron, 2001; Iqbal et al., 2016; Kılıç and Ekici, 2013).

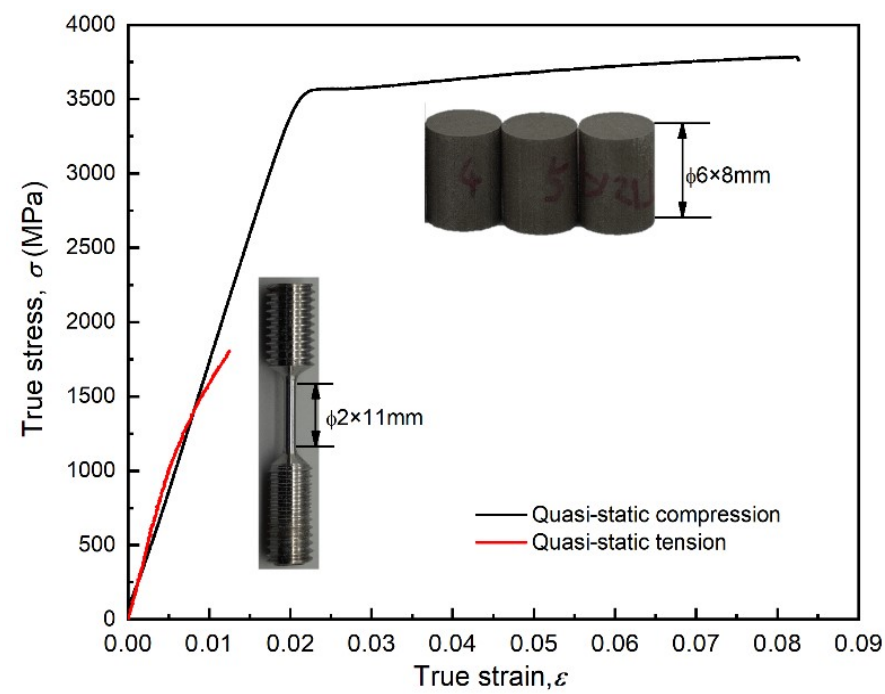

Figure 2: Quasi-static true stress-strain curve of core material

The SiC/metal composite armors used for experiments made the SiC ceramics plates and the Q235 steel plates as respectively the faceplates and backplates, where the SiC plates were covered with a layer of aramid fabric. The SiC with high hardness and low density can erode and fragment the projectile effectively. The size of the SiC ceramic tiles was $200 \mathrm{~mm} \times 200 \mathrm{~mm} \times 15 \mathrm{~mm}$, and the areal density $49.03 \mathrm{~kg} / \mathrm{m}^{2}$. The fabric cover may improve the ballistic performance of ceramic/metal composite armor by partly avoiding premature scattering of ceramic fragments, which had been confirmed by experiments (Rahbek and Johnsen, 2019). The interfaces between the SiC tiles and aramid fabric and metal backplates were bonding together with epoxy adhesives. The increase in areal density when bonding one composite layer to the $\mathrm{SiC}$ was $1.0 \%$ on average. The backplate provided support for the ceramic panel, with $200 \mathrm{~mm} \times 200 \mathrm{~mm} \times 5.77 \mathrm{~mm}$ in size.

\subsection{Ballistic testing}

The ballistic testing system can be divided into five independent parts: $12.7 \mathrm{~mm}$ ballistic gun, velocity measurement system, composite targets, target fixing device, and fragment recovery system, as shown in Figure 3 . The $12.7 \mathrm{~mm}$ ballistic gun fired the projectile by igniting the gun powder. The velocity measurement system obtained the approximate impact velocities of the projectiles by measuring the times when the projectile passed through two light screens with a distance of $2.0 \mathrm{~m}$. The composite targets were fixed in a steel frame with a cover plate to facilitate clamping, shown in Figure 4. Studies have shown that lateral restraint have an obvious effect on the ballistic performance of ceramic (Chi et al., 2015; Hazell et al., 2021; Lundberg et al., 2000; Lynch et al., 2006), but it was not within the research scope of this article. There was a $3 \mathrm{~mm}$ spacing between the ceramic side and the inner wall of the steel frame to ensure that the composite target 
would not receive lateral restraint and pre-stress. The metal frame and the composite target plate in the metal frame were fixed in a collection box, with $510 \mathrm{~mm} \times 525 \mathrm{~mm} \times 405 \mathrm{~mm}$ in size. A layer of wood board with a thickness of $12 \mathrm{~mm}$ was lined on every inner wall of the recovery box to prevent secondary damage caused by the fragments of the bullet core directly hitting the metal shell of the recovery box. These projectiles were planned to be fired at velocities ranging from $400 \mathrm{~m} / \mathrm{s} \sim 830 \mathrm{~m} / \mathrm{s}$.

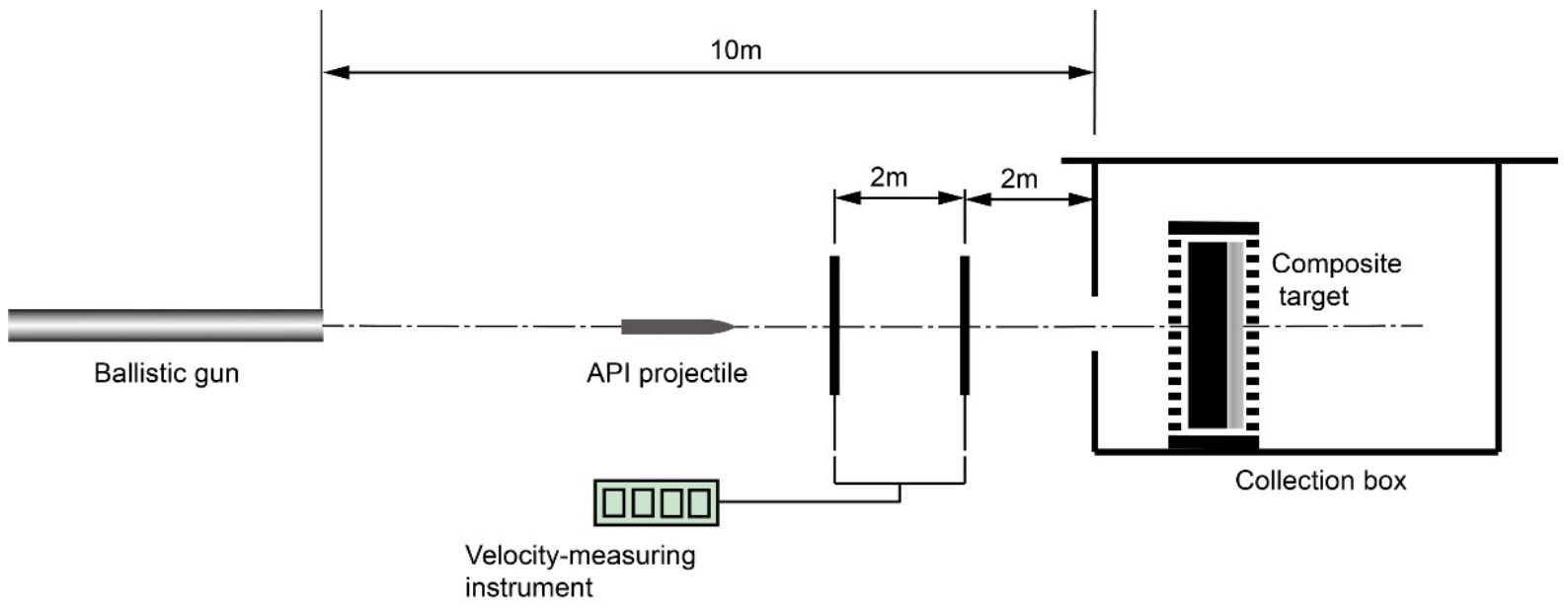

Figure 3: Scheme of the experimental set-ups

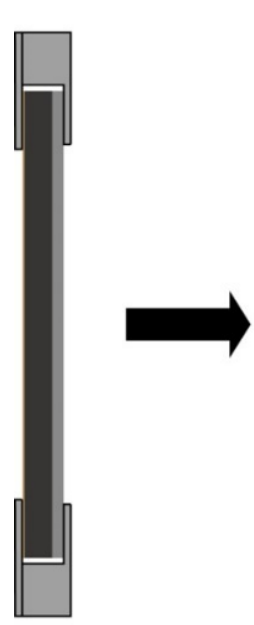

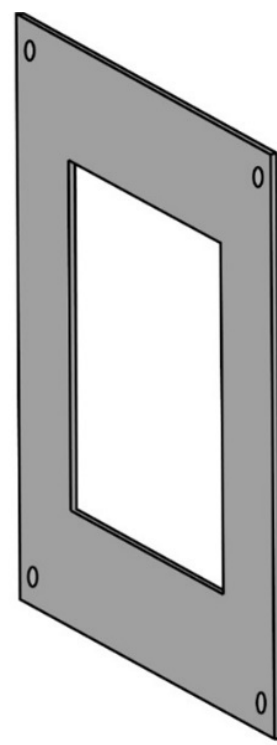

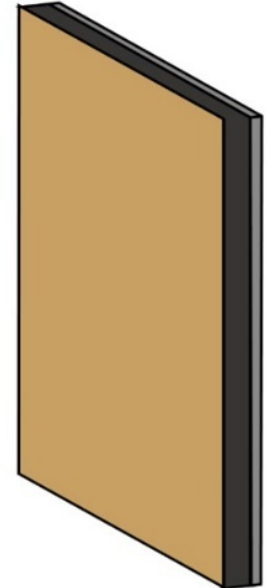

Composite target

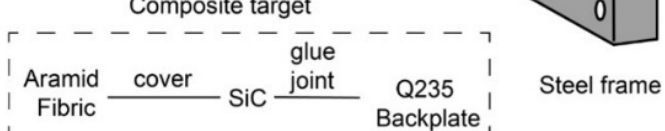

Figure 4: The composite target placed in a steel frame with a cover plate

\subsection{Fragment analysis}

All the fragments in the collection box were collected, including ceramic fragments and core fragments. A magnet was used to separate the core fragments from the ceramic fragments. The resulting core fragments and ceramic fragments were separated by size, using the sieving method. A series of sieves with several sieve sizes were chosen to separate the fragments, including $\mathrm{d}=0.5 \mathrm{~mm}, 1.0 \mathrm{~mm}, 2.0 \mathrm{~mm}$, and $4.0 \mathrm{~mm}$ for core fragments, $\mathrm{d}=0.5 \mathrm{~mm}, 1.0 \mathrm{~mm}, 2.0 \mathrm{~mm}$, $4.0 \mathrm{~mm}, 8.0 \mathrm{~mm}, 12.5 \mathrm{~mm}$, and $25.4 \mathrm{~mm}$ for ceramic fragments. The fragment mass of the different fractions was then measured separately. And each core fragment with a particle size more than $4 \mathrm{~mm}$ was weighed separately.

SEM was used to image the fracture surfaces of remaining projectile cores, the fragments in the middle of the body, and the small fragments probably produced by the head of cores. 


\section{EXPERIMENTAL RESULTS AND ANALYSIS}

\subsection{Ballistic testing}

By adjusting the mass of gunpowder in the cartridge, the ten different impact velocities of the projectiles were $412.6 \mathrm{~m} / \mathrm{s}, 454.7 \mathrm{~m} / \mathrm{s}, 476.7 \mathrm{~m} / \mathrm{s}, 521.8 \mathrm{~m} / \mathrm{s}, 577.4 \mathrm{~m} / \mathrm{s}, 600.3 \mathrm{~m} / \mathrm{s}, 672.9 \mathrm{~m} / \mathrm{s}, 701.0 \mathrm{~m} / \mathrm{s}, 756.1 \mathrm{~m} / \mathrm{s}$, and $802.2 \mathrm{~m} / \mathrm{s}$ respectively.

The effect of ballistic impact on ceramic fracture was similar under different impact velocities of projectiles. The fracture of the ceramic plate was caused by macroscopic cracks, which can be divided into three types. The first type of cracks were radial cracks from the position of the projectile impacting the target outward. The second type of cracks were multiple circumferential cracks with the centers of the circles at the positions of projectiles impacting targets. The last ones were the conical cracks extending outward and toward the backplates from the projectile's impact location, shown in Figure 5. And with the increase of impact velocity, the fragmentation degree of ceramic plate increased obviously.

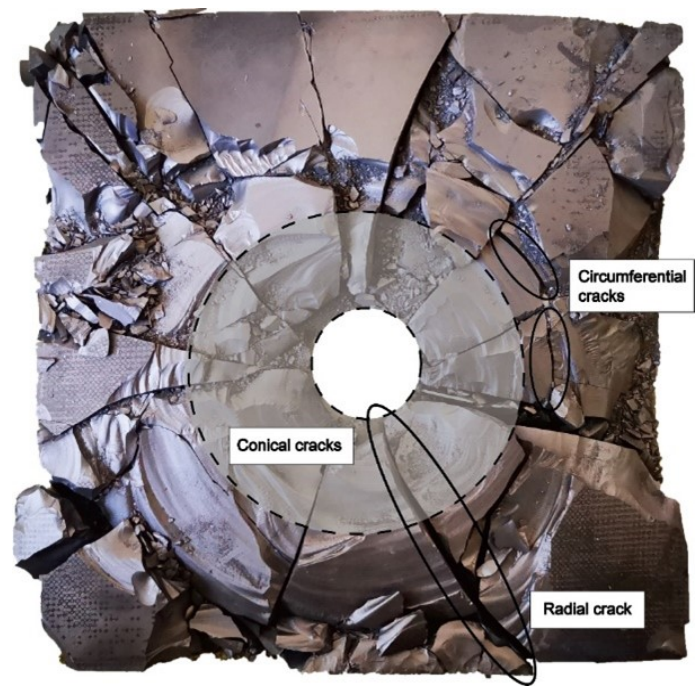

Figure 5: The backsides of the ceramic targets showing the extent of damage after projectile impact

All the composite targets were not penetrated when the impact velocity was below the ballistic limit. The deformation mode of the backplate was bulging-dishing. With the increase of projectile velocity, the deformation w of the backplate increased correspondingly, shown in Figure 6. The coordinate origin is the initial position of the maximum displacement position of the backplate.

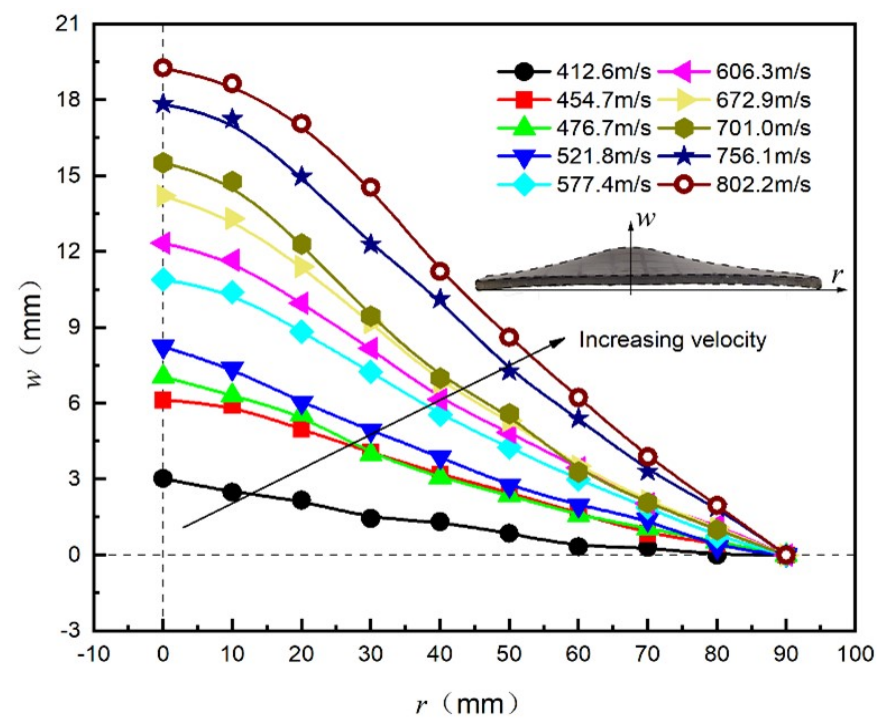

Figure 6: The deformation field of the backplate 
In the process of projectile target interaction, the backplate mainly absorb energy through bending and stretching deformation. It is assumed that the deformation of the backplate was axisymmetric. All bending and stretching deformation energy absorption can be expressed as follows (Zaera and Sánchez-Gálvez, 1998):

$$
E_{p}=\pi h_{b} \delta Y_{b}\left(\frac{2}{3} h_{b}+\frac{1}{2} \delta\right)
$$

Where $h_{b}$ is the plate thickness, $\delta$ is the central backplate deformation, and $Y_{b}$ is dynamic yield stress. For Q235 steel, the value of $Y_{b}$ is 340MPa (Lin et al., 2013). The maximum central displacement of each backplate is obtained from Figure 6 . The value of deformation energy can be easily calculated by Eq.(1).

As the initial kinetic energy of the core increase, the deformation energy of the backplate and its proportion in the initial kinetic energy of the core increase. And the deformation energy of the backplate increases near linearly with the initial kinetic energy of the core. As shown in Figure 7.

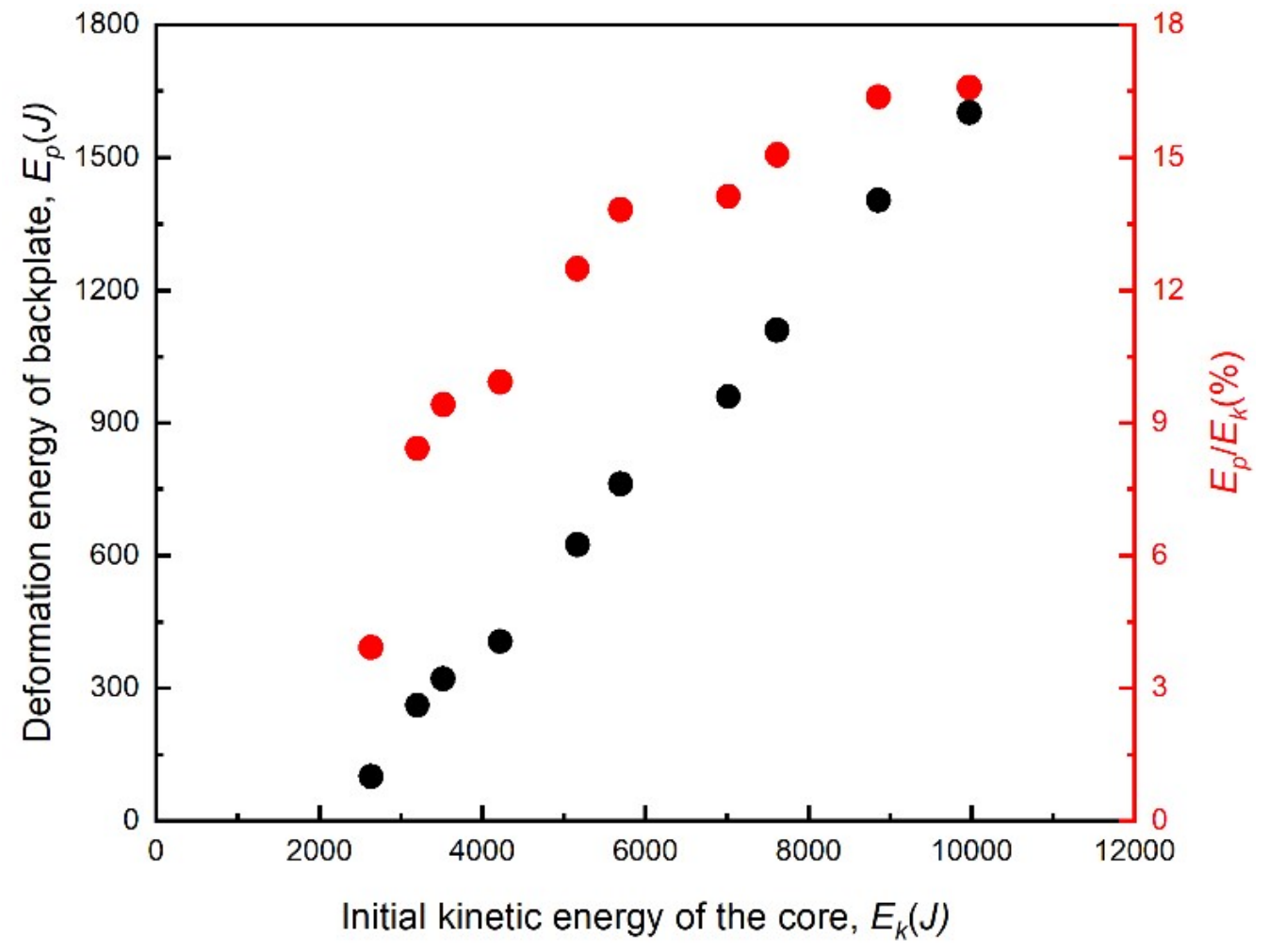

Figure 7: Energy absorption of the backplate

\subsection{Fragments}

\subsubsection{Core fragment}

The high rigidity and high brittleness of the $12.7 \mathrm{~mm}$ API core indicates that it would fragment under the impact (Rahbek and Johnsen, 2019; Rakvåg et al., 2013; Rakvåg et al., 2014). The rigid-brittle projectile core fragments were collected after the penetration with a collection box and then separated by size. For all the tests, a few larger and many smaller fragments of core were collected, as shown in Table 1 . The mass of the largest fragments was generally produced at the tail of the core, which was also the main part of providing the subsequent penetration ability. Rahbek (Rahbek and Johnsen, 2019) and Savio (Savio et al., 2011; Savio et al., 2015) observed the same phenomenon, although the $7.62 \mathrm{~mm}$ AP different projectile penetrated the different ceramic composite targets. 
Table 1 Recovered projectile core fragments

The image of fragments

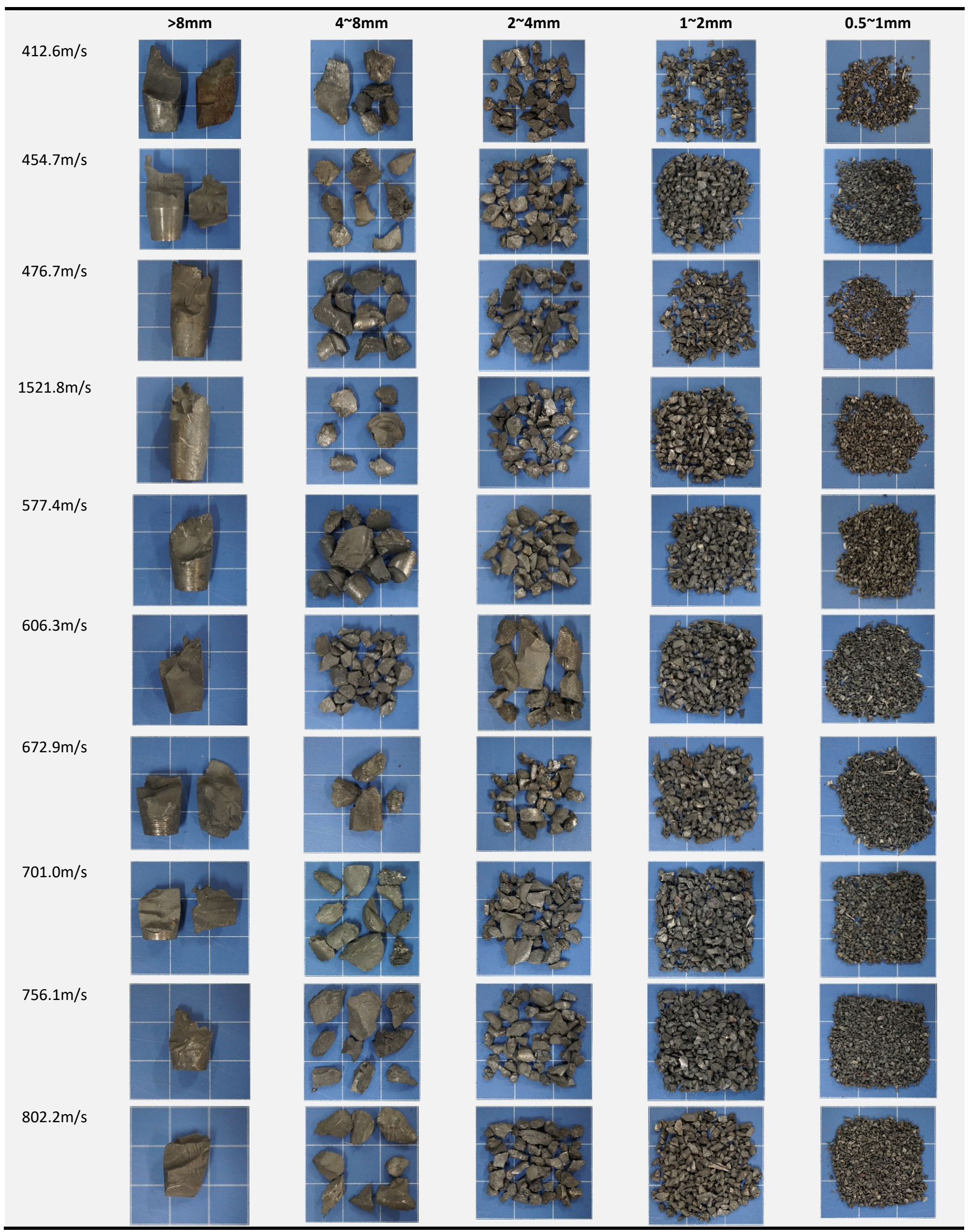


Macrocracks were found near the maximum mass fragment near the projectile/target interaction zone, as shown in Figure 8. This observation and the formation of small fragments indicated the high-stress state of the projectile core head.

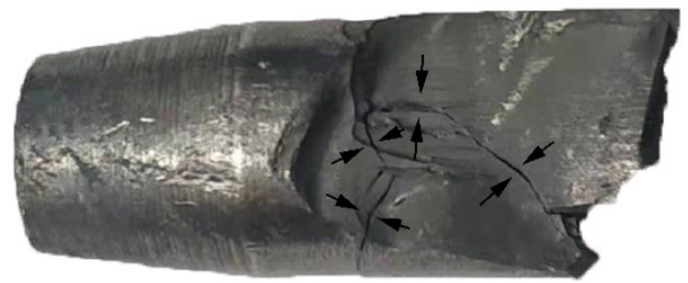

Figure 8: The largest fragment with a crack

\subsubsection{Failure mechanism of the cores}

The rigid-brittle cores have broken into a large number of fragments after impacting aramid fabric/SiC/metal composite armors. The fracture surface of the residual projectile and the debris from the middle of the projectiles were selected for macro observation, as shown in Figure 9 and Figure 10. There was no obvious plastic deformation around the fracture surface, and obvious radial marks can be observed on each surface, which is one of the macroscopic manifestations of cleavage fracture, and cleavage fracture was the failure mode caused by brittle tensile stress. The results show that the tensile stress failure is the main fracture mode of the fragments in the middle and tail of the core. It should be noted that the surface in Figure 9 (b) is formed by the intersection of several independent fracture surfaces, indicating that the surface was caused by multiple fracture failures.

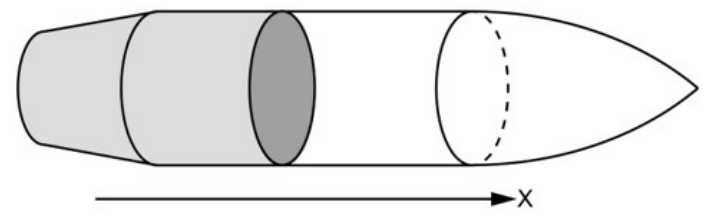

(a)
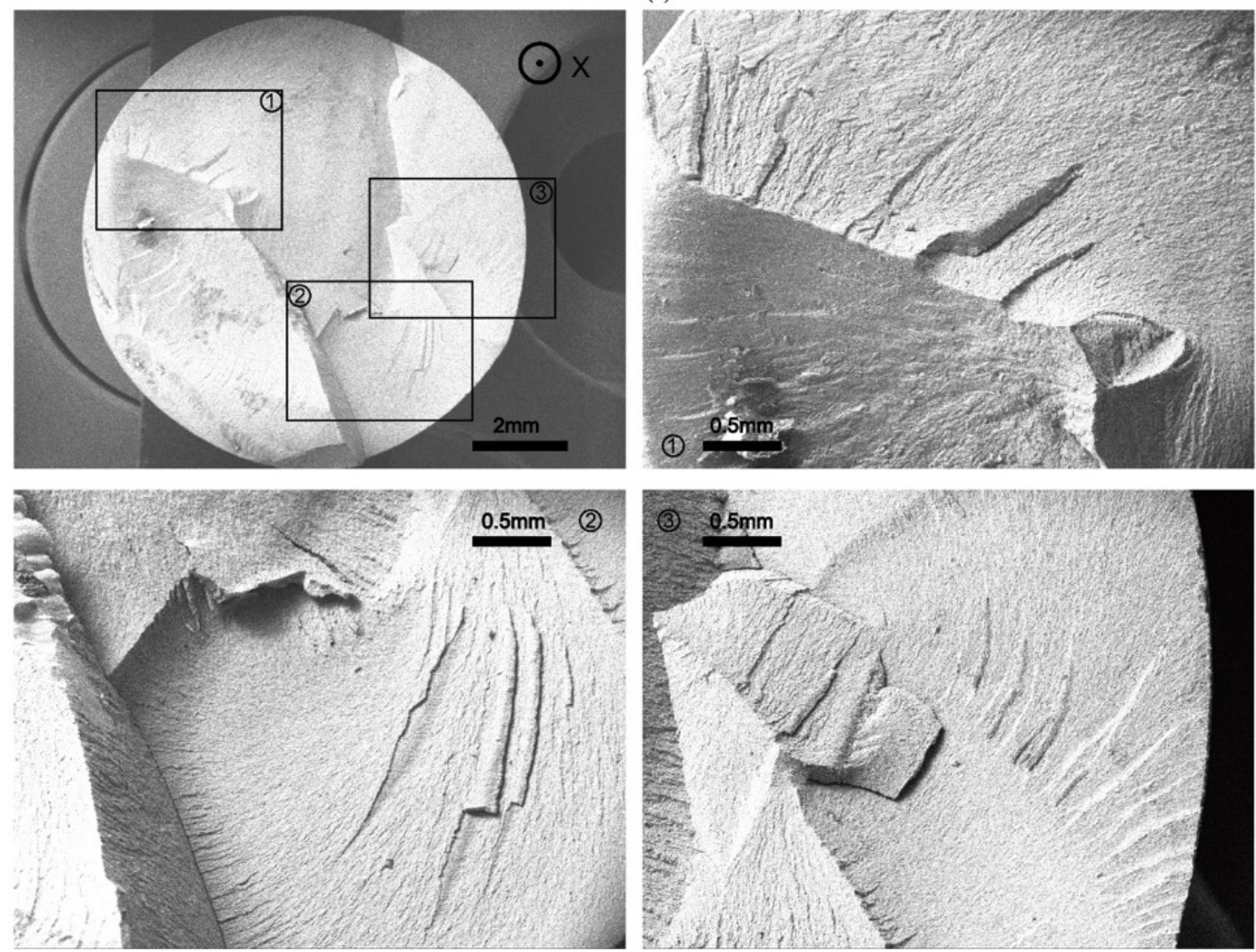

(b)

Figure 9: Fracture surface of residual projectile: sample sampling diagram (a) and SEM images of fracture surface (b) 


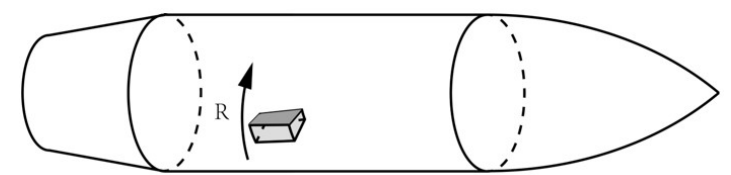

(a)

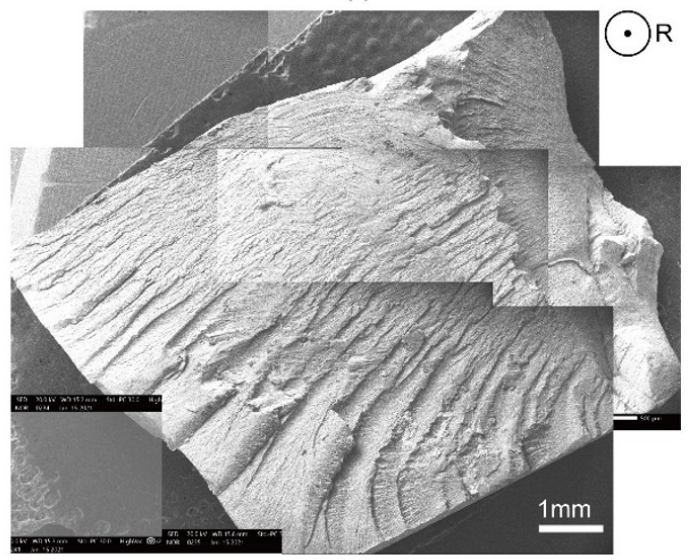

(b)

Figure 10: Fracture surface of the projectile fragment: sample sampling diagram (a) and SEM images of fracture surface (b)

When all core fragments were examined, cracks were found in the head of some residual cores, shown in Figure 11, but no cracks were found at the head of others. In order to study these failure mechanisms of cores, one largest core was cut along its longitudinal axis. Close observation on the longitudinal cross section of the resulting core showed that there were two different failure patterns located at two independent locations in the projectile. The first type of failure pattern is marked as " $A$ " in Figure 11 (b). A large amount of Pb and Al were found in the crevice by Energy Dispersive Spectroscopy (EDS), which were from the Pb sleeve of the API projectile and the aluminum alloy backplate, respectively. This indicated that the domain " $A$ " was formed by the accumulation of fragments. The crack in zone B was formed by the action of stress waves, the Poisson effect, and their interaction.

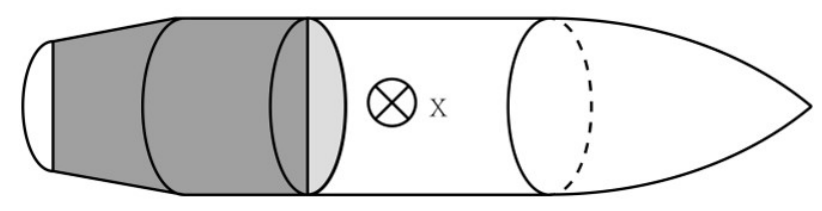

(a)

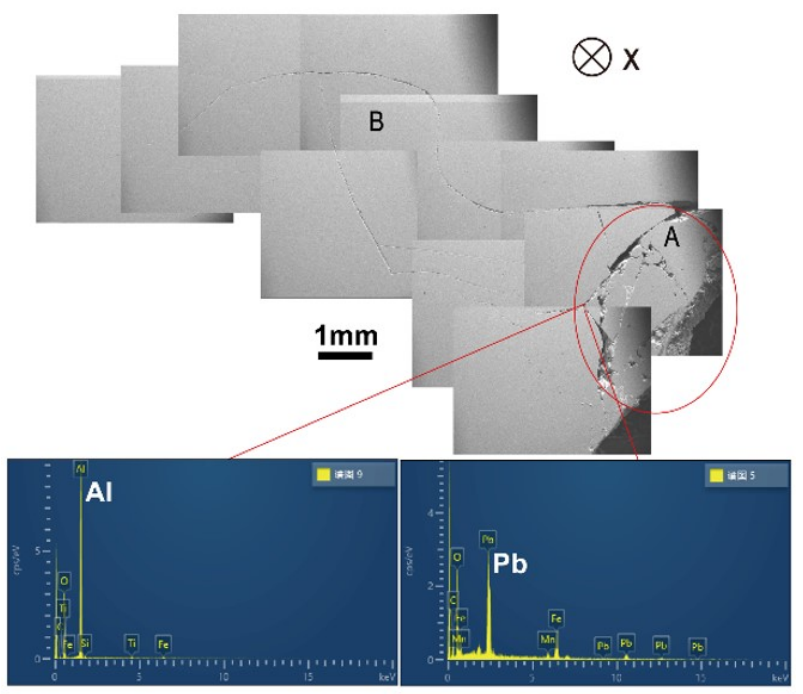

(b)

Figure 11: The longitudinal cross-section of the residual projectile: sample sampling diagram (a) and SEM and EDS images of the residual projectile (b) 
Figure 12 shows the SEM analysis results of a fragment with an equivalent diameter of less than $2 \mathrm{~mm}$. Local shear dimples appeared on the fragment of the core, which indicated that there was a certain degree of local impact toughness in the impact process of the core.
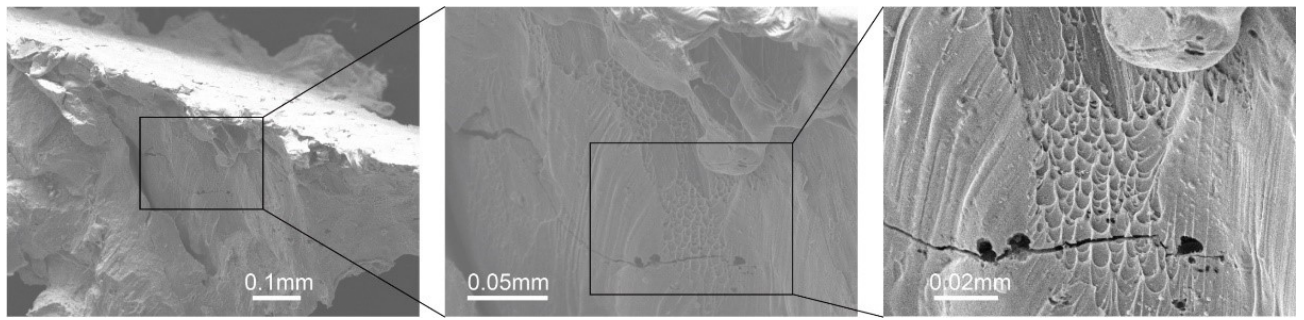

Figure 12: Local shear dimples appear in the core fragments

\subsubsection{Mass distribution of core fragments}

There are ten effective test data, we obtained, which velocity ranges from $412.6 \mathrm{~m} / \mathrm{s}$ to $802.2 \mathrm{~m} / \mathrm{s}$. Table 2 shows the total fragment mass in different size fractions after separating by size. We thought the experiment is credible because the mass percentage of core fragments collected was higher than $90 \%$ except for one shot (only higher than $82 \%$ ). This shows that less than $10 \%$ fragments in mass were lost during the experiment process, some of these fragments may lose during the recovery of the fragments from the collection box. However, no important fragments were found outside the collection box, and the lost mass was likely to appear in the form of finer particles. But this was not enough, we thought, to have any effect on the distribution law of the fragments. The largest proportion of mass was found in the fraction larger than $4 \mathrm{~mm}$ in particle size, including the largest core fragment.

For the smaller size fractions, an increasingly lower resulting mass was measured. This is also illustrated in Figure 13 (the figure is based on the data in Table 2). The mass distribution of fragments is velocity-dependent. With the increase of impact velocity, the mass in the largest size fraction decrease, while the mass in the smaller size fractions (from 1 to 2 $\mathrm{mm}, 0.5$ to $1 \mathrm{~mm}$, and smaller than $0.5 \mathrm{~mm}$ in size) increased.

Table 2 The mass of residual core fragment of size fractions

\begin{tabular}{|c|c|c|c|c|c|c|c|c|c|}
\hline \multirow{2}{*}{ Sample No. } & \multirow{2}{*}{ Target type } & \multirow{2}{*}{ Velocity (m/s) } & \multicolumn{7}{|c|}{ Core fragment mass(g) } \\
\hline & & & All & $\%$ & $>4 \mathrm{~mm}$ & $2-4 \mathrm{~mm}$ & $1-2 \mathrm{~mm}$ & $0.5-1 \mathrm{~mm}$ & $<0.5 \mathrm{~mm}$ \\
\hline No.1 & $15 \mathrm{~mm}+5.77 \mathrm{~mm}$ & 412.6 & 29.54 & 98.14 & 21.56 & 3.71 & 2.55 & 0.94 & 0.78 \\
\hline No.2 & & 454.7 & 30.05 & 99.83 & 18.42 & 4.15 & 4.32 & 1.72 & 1.44 \\
\hline No.3 & & 476.7 & 28.58 & 94.95 & 19.78 & 3.64 & 2.64 & 1.24 & 1.28 \\
\hline No.4 & & 521.8 & 27.58 & 91.63 & 17.00 & 3.64 & 3.92 & 1.61 & 1.41 \\
\hline No.5 & & 577.4 & 27.13 & 90.13 & 16.46 & 3.54 & 3.78 & 2.02 & 1.33 \\
\hline No.6 & & 606.3 & 27.91 & 92.72 & 14.74 & 4.33 & 4.12 & 2.35 & 2.37 \\
\hline No.7 & & 672.9 & 27.5 & 91.36 & 15.71 & 2.91 & 3.93 & 2.3 & 2.65 \\
\hline No.8 & & 701.0 & 27.3 & 90.70 & 13.23 & 4.42 & 4.65 & 2.16 & 2.84 \\
\hline No.9 & & 756.1 & 28.42 & 94.42 & 10.99 & 4.6 & 5.63 & 3.12 & 4.08 \\
\hline
\end{tabular}

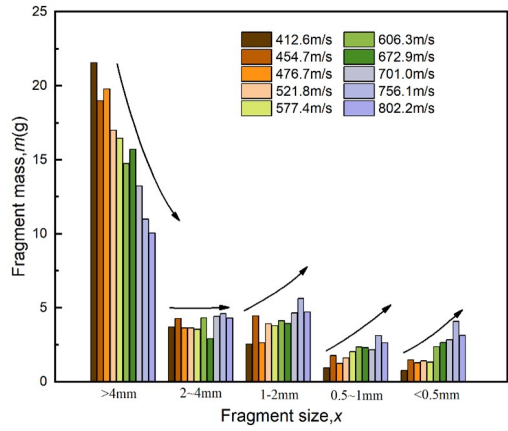

Figure 13: Fragments distribution of core at different projectiles velocities 


\subsubsection{Mass distribution of ceramic fragments}

The results from the mass measurement of the different fragment sizes, after separation by sieves, are given in Figure 14. The experiment was credible, we thought, on account of the mass percentage of ceramic fragments collected was higher than $94 \%$. The mass proportion of lost fragments was less than $6 \%$, which was not enough to influence the distribution law of the fragments. Figure 14 shows that the velocity-dependent of the mass distribution of ceramic fragments is obvious. With the increase of the impact velocity, the mass of fragments higher than $25.4 \mathrm{~mm}$ decrease, and the ceramic fragments less than $25.4 \mathrm{~mm}$ increase.

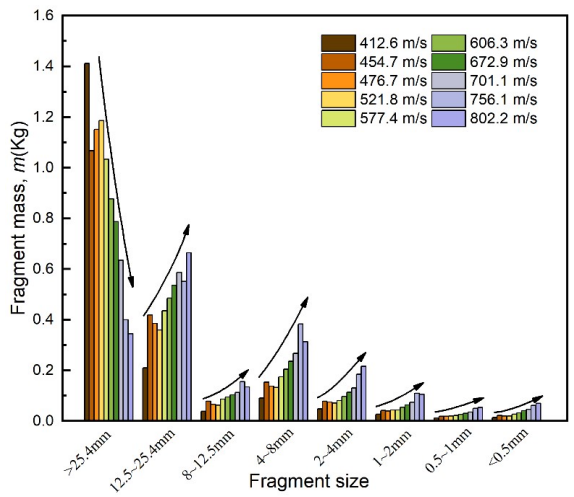

Figure 14: Fragments distribution of ceramic at different projectiles velocities

\section{FRAGMENTS DISTRIBUTION}

\subsection{The models of fragments distribution}

It's difficult to predict the fracture behavior of a material, especially for brittle solids under high stress and strain rate. In the study of fragment mass distribution, the probability density function is sensitive to the measurement result of every fragment, while the measurement result of a single fragment has a certain measurement error. Some of the fragments can be lost within the allowable range of the experiment, which both would cause a great error to the mode of fragment mass distribution law and fitting result. In contrast, the fragment cumulative mass distribution can ignore these problems. Therefore, this study focuses on obtaining the cumulative fragments mass distribution with different fragment fractions, but the mass distribution of single fragment or the number distribution of fragments.

In order to obtain the fragment cumulative mass distribution of core and ceramic after impact, the multi-stage screening method is used to screen and weigh the fragments with different particle sizes. Fragments distribution can be described by a probability function $f(x)$, and the cumulative distribution function is:

$$
F(x)=\int_{0}^{x} f(x) d x
$$

Based on the statistics of the fragments produced by the material fragmentation test, scholars have established various correlation functions to describe the fragment distribution. All these functions can be classified into two types: exponentiallike functions and power-like functions. The exponential-like functions are mainly used to describe the fragment distribution of metals and other ductile materials, including Lineau and Mott-linfoot distribution and others. Weibull distribution is the most frequently used exponential-like distribution function(Li et al., 2018), The Weibull type distribution is described as:

$$
G(x)=1-\exp \left(-(x / \lambda)^{k}\right)
$$

where $k$ is the shape parameter, in the range of 0.5 to 1.5. The Weibull distribution includes the Lineau distribution and Mott-Linfoot distribution where $k$ equals to 1 and 2, respectively. The scale length $\lambda$ represents the average characteristic fragment size which positively correlated with the mean fragment size.

The distribution law of exponential function is only used to describe the fragmentation of ductility materials such as metallic. When highly brittle materials such as glass or ceramic undergo catastrophic fragmentation, however, 
fragment distribution follows the power law rather than the exponential distribution. The Rosin-Rammler(P. Rosin, 1933) distribution is commonly written as a cumulative mass fraction, the mass of fragments with less than a size $x$ :

$$
M(\leq x)=M_{0}\left[1-e^{-(x / \lambda)^{k}}\right]
$$

where $M_{0}$ is the sample mass before crushing, $x$ is the fragment equivalent diameter, $\lambda$ is the average characteristic fragment size, the shape parameter $k$ ranges between about 0.5 and 1.5. The limiting form of the Rosin-Rammler distribution:

$$
M(\leq x)=M_{0}(x / \lambda)^{k}
$$

is usually attributed to Schuhmann (Grady, 2008). The Schuhmann distribution can describe the results of fragment distribution of most brittle materials. The shape parameter $k$ is usually obtained by fitting the experimental data, and has no practical physical significance.

To demonstrate the differences between different distributions, the results of sample No.1 are presented in Figure 15. In Figure 15, The lienau cumulative distribution function taking a shape parameter of $k=1.0$, the Mott-linfoot cumulative distribution function taking a shape parameter of $k=0.5$, the Weibull cumulative distribution function fitted a shape parameter of $k=1.049$, the power-law cumulative distribution function is plotted for the comparison between the experimental results. As expected, the power-law distribution gives an overall better consistency with the experiments than other distributions.

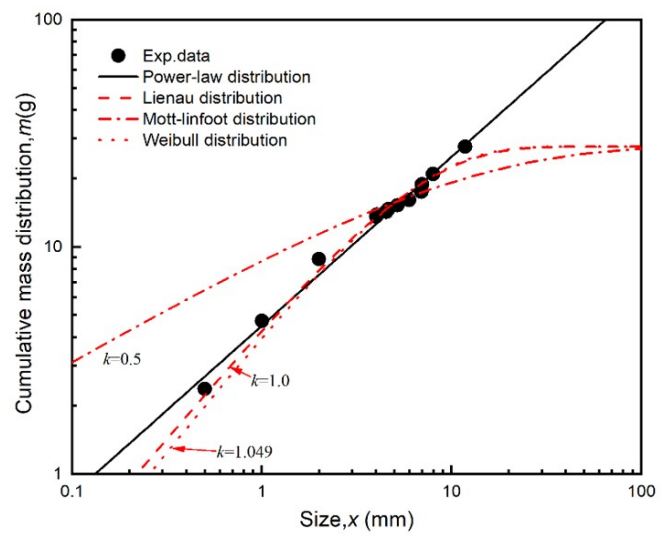

Figure 15: Core fragment mass cumulative of sample No.1 and different fitting distributions

Generally, to determine the value of shape parameter k, EQ.(2) can be written in logarithmic form, as:

$\lg (M(\leq x))=k \lg (x)+\lg \left(\frac{M_{0}}{\lambda^{k}}\right)$

The slope of the straight line after the logarithm treatment is the shape parameter $k$ of the Schuhmann distribution.

\subsection{Fragments cumulative distribution}

Based on the SEM observation of the fragments collected after the test in 3.2.2, it was determined that the fragmentation mode of the core is a brittle fracture. And SiC ceramic was a typical brittle material (Chi et al., 2015; Hazell et al., 2021). The distributions of the fragments of the core and ceramic were fitted by Schuhmann distribution.

\subsubsection{Core fragments cumulative distribution}

After collecting and sieving all core fragments, the fragments in the size range of less than $0.5 \mathrm{~mm}$, from $0.5 \mathrm{~mm}$ to $1 \mathrm{~mm}$, from $1 \mathrm{~mm}$ to $2 \mathrm{~mm}$, and from $2 \mathrm{~mm}$ to $4 \mathrm{~mm}$ were weighed collectively, and the fragments larger than $4 \mathrm{~mm}$ were weighed separately. Figure 16 (a) (b) showed the cumulative mass distribution under different impact velocities and their logarithm form's linear fitting results, respectively. The abscissa of Figure $16(\mathrm{a})$ is the equivalent diameter of the core fragments. The sieve sizes for fragments less than $4 \mathrm{~mm}$, the diameter of sphere fragment with equal mass for large than 
$4 \mathrm{~mm}$ is introduced as the equivalent diameter of fragments because the fragments were irregular. It can be seen from Figure 16(b) that there is an obvious linear relationship between the logarithm of cumulative mass of core fragments and the logarithm of the equivalent diameter of fragments. The results show that the cumulative mass distribution of core fragments after $12.7 \mathrm{~mm}$ API projectile penetrating fabric/SiC/metal composite armor follows the Schuhmann distribution.

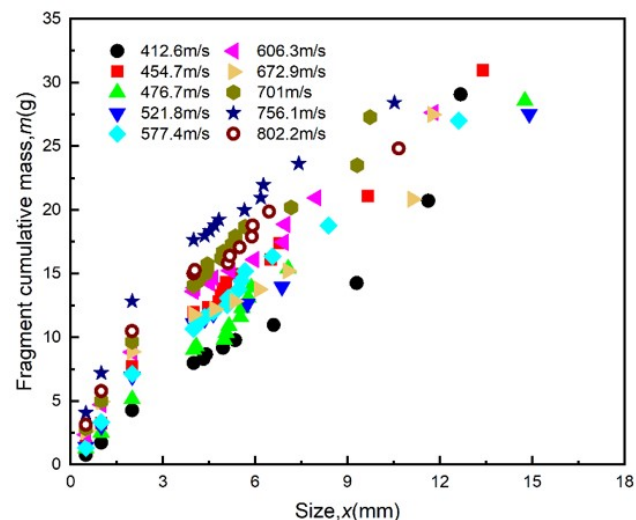

(a)

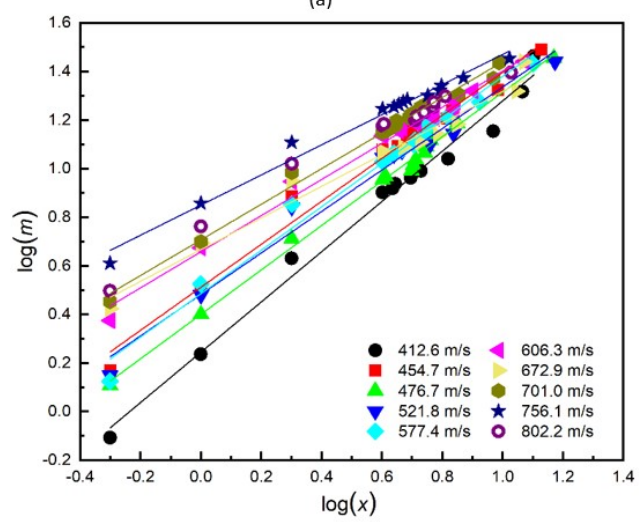

(b)

Figure 16: Fragment cumulative mass distribution for core under different impact velocities(a) and its logarithm form(b).

The fitting values of the shape parameter $k$ and the average characteristic fragment size $\lambda$ under different velocities are shown in Figure 17. With the increase of the projectiles' impact velocities, the shape parameter $k$ and the average characteristic fragment size $\lambda$ show a decreasing trend. The decrease of $k$, with the increase of impact velocity, indicate the mass increase for small debris and decrease for large debris. That is to say, the larger the impact velocity is, the more the small mass fragments are.

During the interaction between the projectile and the target plate, part of the kinetic energy of the projectile is transformed into the fracture energy of the core. With the increase of the projectiles' impact velocities, that is, the initial kinetic energy, the core will produce more fracture surfaces to consume kinetic energy, resulting in more and smaller fragments.

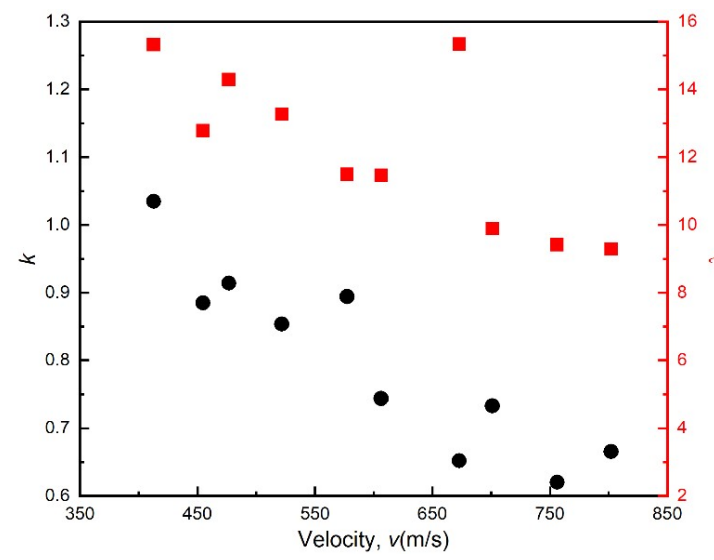

Figure 17: The fitting values of the shape parameter $k$ and the average characteristic fragment size $\lambda$ 


\subsubsection{Ceramic fragments cumulative distribution}

Sieve all ceramic fragments with the sieve sizes, including $0.5 \mathrm{~mm}, 1.0 \mathrm{~mm}, 2.0 \mathrm{~mm}, 4.0 \mathrm{~mm}, 8.0 \mathrm{~mm}, 12.5 \mathrm{~mm}$, and $25.4 \mathrm{~mm}$. The fragments in the size range of less than $0.5 \mathrm{~mm}$, from $0.5 \mathrm{~mm}$ to $1 \mathrm{~mm}$, from $1 \mathrm{~mm}$ to $2 \mathrm{~mm}$, from $2 \mathrm{~mm}$ to $4 \mathrm{~mm}$, from $4 \mathrm{~mm}$ to $8 \mathrm{~mm}$, from $8 \mathrm{~mm}$ to $12.5 \mathrm{~mm}$, from $12.5 \mathrm{~mm}$ to $25.4 \mathrm{~mm}$ and larger than $25.4 \mathrm{~mm}$ were weighed collectively. Figure 18 (a) and 18 (b) show the cumulative mass distribution of ceramic fragments under different impact velocities and the linear fitting results of their logarithm form, respectively. The abscissa of Figure 18 (a) mean the ceramic fragment's equivalent diameter, which is equal to the sieve size.

There are two distinct fragmentation mechanisms of ceramics under impact: one mechanism produce small fragments related to the combination of cracks originating from material defects, and the other mechanism produce large fragments related to structural failure (e.g., Radial and circumferential cracks). In other words, both blocky and shard fragments are produced during the ceramic plate against the projectile. The ceramic plate can be divided into two parts according to the fragmentation mechanisms: the ceramic-cone fragmentation part, and the tensile stress fragmentation part. The ceramic-cone fragmentation part bears the role of anti-projectile.

Interestingly, the ceramic fragments follow the Schuhmann distribution only for the fragments less than $25.4 \mathrm{~mm}$. The reason is that the fragments larger than $25.4 \mathrm{~mm}$ were produced by the intersection of radial cracks and circumferential cracks under the action of stress wave of tensile stress fragmentation part. The fragment size of the ceramic-cone fragmentation part was generally less than $25.4 \mathrm{~mm}$ due to the high-pressure effect of the projectile on ceramic. It can be seen from Figure 18 (b) that there is an obvious linear relationship between the logarithm of cumulative mass of ceramic fragments and the logarithm of the equivalent diameter of fragments. The results show that the cumulative mass distribution of ceramic fragments after $12.7 \mathrm{~mm}$ API projectile penetrating fabric/SiC/metal composite armor follows the Schuhmann distribution.

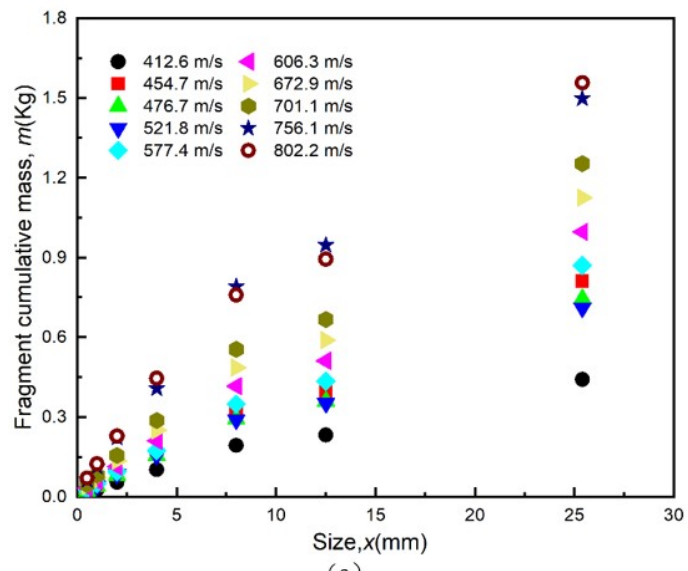

(a)

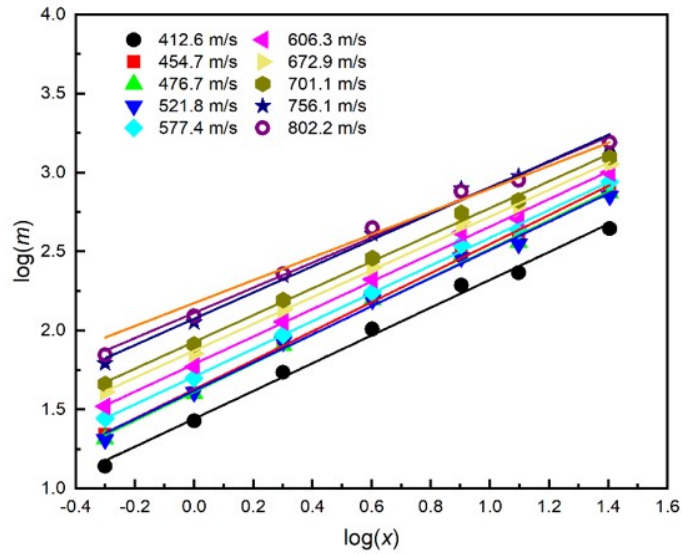

(b)

Figure 18: Fragment cumulative mass distribution for ceramic under different impact velocities(a) and its logarithm form(b).

Figure 19 shows that, with the increase of the impact velocity, the shape parameter $k$ of the Schuhmann distribution has a decreasing trend, but the change is small in the range of $0.858 \pm 0.062$. It means that the fitting lines in Figure 18 (b) are basically parallel. And the average characteristic fragment size $\lambda$ of ceramic fragments is in the range of $24.006 \pm$ 1.229 , with the impact velocities of projectiles ranging from $412.6 \mathrm{~m} / \mathrm{s}$ to $802.2 \mathrm{~m} / \mathrm{s}$. To sum up, with the increase of the 
impact velocity, the total mass of fragments less than $25.4 \mathrm{~mm}$ increase. Still, the mass proportion of fragments in different fractions mi/M is unchanged basically, shown in Figure 20, especially for fragments less than $12.5 \mathrm{~mm}$.

With the increase of projectiles' impact velocities, the ceramic plates need to produce more fracture surfaces to consume the projectiles' kinetic energy. Although the shape parameters $k$ and the average characteristic fragment sizes $\lambda$ do not change significantly at different speeds, more fracture surfaces, and more energy consumption have produced due to the total mass of fragments increases.

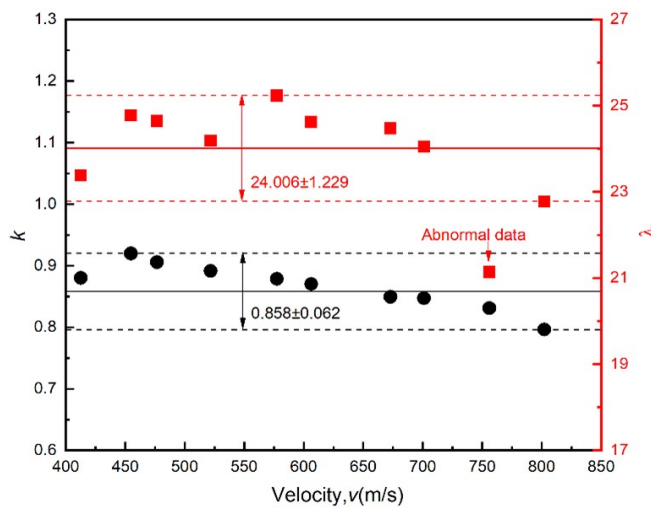

Figure 19: The fitting values of the shape parameter $k$ and the average characteristic fragment size $\lambda$ for ceramic fragments

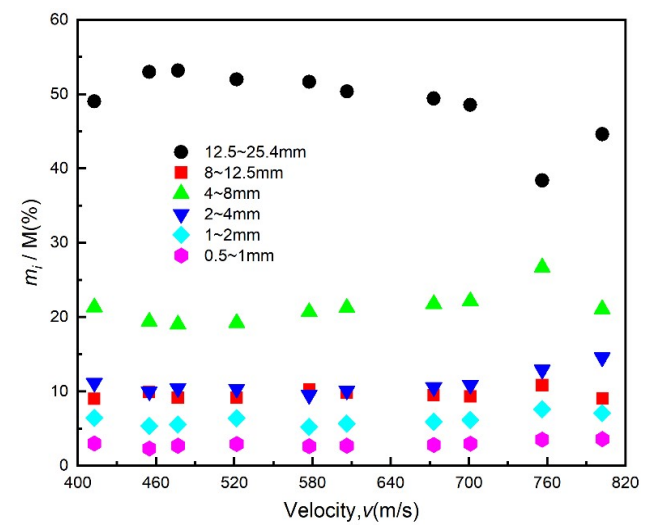

Figure 20: Mass proportion of fragments in different fractions

\section{CONCLUSIONS}

The $12.7 \mathrm{~mm}$ API projectiles impacting SiC Ceramic/Q235 steel composite targets were carried out. The fracture model and failure mechanism of $12.7 \mathrm{~mm}$ API projectiles cores, on impacting composite targets, were studied through the microstructural examination of the failed projectile cores. The fragments mass distribution law of core and ceramic fragments were studied by collecting and separating the core and ceramic fragments through a series of sized sieving screens allowed. Studying the fragmentation characteristics of the projectile core and ceramic plate is important to quantify and predict the erosion and fragmentation of ones. This can help us to understand the subsequent penetration ability and penetration mechanism of the projectiles. The main conclusions are summarized as follows:

1. The failure mode of the ceramic plate is a brittle fracture. The macroscopic cracks include radial crack from the position of projectile impacting target outward, multiple circumferential cracks with the center of the circle at the position of projectile impacting target, and conical crack extending outward and toward the backplate from the projectile's impact location.

2. The deformation mode of the backplate is bulging-dishing. As the initial kinetic energy of the core increase, the deformation energy of the backplate and its proportion in the initial kinetic energy of the core increase. And the deformation energy of the backplate increases near linearly with the initial kinetic energy of the core. 
3. The tensile stress failure is the main fracture mechanism of the fragments in the middle and tail of the core. Local shear dimples appear on the fragments of the core head, which indicates a certain degree of local impact toughness in the impact process of the core.

4. The relationship between the cumulative mass and the core fragments' equivalent diameter follows the Schuhmann power law distribution. With the increase of the impact velocity, the shape parameter $k$ and the average characteristic size $\lambda$ reduce gradually.

5. The ceramic fragments follow the Schuhmann distribution law only for the fragments less than $25.4 \mathrm{~mm}$. With the increase of the impact velocity, the shape parameter $k$ and the average characteristic size $\lambda$ reduce slightly. The mass proportion of fragments in different fractions is unchanged basically, especially for fragments less than $12.5 \mathrm{~mm}$.

\section{Acknowledge}

The author discloses the receipt of the following financial support for the research, authorship, and/or publication of this article: This research work was financially supported by the National Natural Science Foundation of China (Grant numbers 11772160 and 11472008), the Opening Project of State Key Laboratory of Explosion Science and Technology of Beijing Institute of Technology (KFJJ18-01M) and the National Natural Science Foundation of China (Grant number 11802001).

Author's Contribuitions: Conceptualization, Xiaodong Wang, Zhaoxiu Jiang and Guangfa Gao; Data curation, Xiaodong Wang, Yilei Yu and Kun Zhong; Formal Analysis, Xiaodong Wang, Yilei Yu and Kun Zhong; Funding acquisition, Guangfa Gao; Investigation, Xiaodong Wang, Yilei Yu, Kun Zhong and Zhaoxiu Jiang; Methodology, Xiaodong Wang and Guangfa Gao; Validation, Xiaodong Wang, Yilei Yu, Kun Zhong and Zhaoxiu Jiang; Writing - original draft, Xiaodong Wang, Yilei Yu and Kun Zhong; Writing - review \& editing, Zhaoxiu Jiang and Guangfa Gao.

Editor: Marcílio Alves

\section{References}

Ali, M. W., Mubashar, A., Uddin, E., Haq, S. W. U., \& Khan, M. (2017). An experimental and numerical investigation of the ballistic response of multi-level armour against armour piercing projectiles. International Journal of Impact Engineering. 110: 47-56.

Børvik, T., Forrestal, M. J., \& Warren, T. L. (2010). Perforation of 5083-H116 Aluminum Armor Plates with Ogive-Nose Rods and $7.62 \mathrm{~mm}$ APM2 Bullets. Experimental Mechanics. 50(7): 969-978.

Chi, R., Serjouei, A., Sridhar, I., \& Geoffrey, T. E. B. (2015). Pre-stress effect on confined ceramic armor ballistic performance. International Journal of Impact Engineering. 84: 159-170.

Chocron, S. (2001). Impact of the 7.62-mm APM2 projectile against the edge of a metallic target. International Journal of Impact Engineering(25): 423-437.

Demir, T., Übeyli, M., \& Yıldırım, R. O. (2008). Investigation on the ballistic impact behavior of various alloys against $7.62 \mathrm{~mm}$ armor piercing projectile. Materials \& Design. 29(10): 2009-2016.

Di Benedetto, G., Matteis, P., \& Scavino, G. (2018). Impact behavior and ballistic efficiency of armor-piercing projectiles with tool steel cores. International Journal of Impact Engineering. 115: 10-18.

Grady, D. E. (2008). Fragment size distributions from the dynamic fragmentation of brittle solids. International Journal of Impact Engineering. 35(12): 1557-1562.

Hazell, P. J., Wang, H., Lin, T., Saleh, M., Luzin, V., Kader, M. A., Saadatfar, M., Ameri, A., \& Ellis, C. (2021). On the improvement of the ballistic performance of a silicon carbide tile through pre-stress: Experiments and simulations. International Journal of Impact Engineering. 151: 103836.

Hogan, J. D., Farbaniec, L., Mallick, D., Domnich, V., Kuwelkar, K., Sano, T., McCauley, J. W., \& Ramesh, K. T. (2017). Fragmentation of an advanced ceramic under ballistic impact: Mechanisms and microstructure. International Journal of Impact Engineering. 102: 47-54. 
Holmen, J. K., Johnsen, J., Jupp, S., Hopperstad, O. S., \& Børvik, T. (2013). Effects of heat treatment on the ballistic properties of AA6070 aluminium alloy. International Journal of Impact Engineering. 57: 119-133.

Holmen, J. K., Solberg, J. K., Hopperstad, O. S., \& Børvik, T. (2017). Ballistic impact of layered and case-hardened steel plates. International Journal of Impact Engineering. 110: 4-14.

Iqbal, M. A., Senthil, K., Sharma, P., \& Gupta, N. K. (2016). An investigation of the constitutive behavior of Armox 500T steel and armor piercing incendiary projectile material. International Journal of Impact Engineering. 96: 146-164.

Jung, J., Cho, Y. J., Kim, S., Lee, Y., Kim, H., Lim, C., \& Park, Y. H. (2020). Microstructural and mechanical responses of various aluminum alloys to ballistic impacts by armor piercing projectile. Materials Characterization. 159: 110033.

Kılıç, N., Bedir, S., Erdik, A., Ekici, B., Taşdemirci, A., \& Güden, M. (2014). Ballistic behavior of high hardness perforated armor plates against 7.62mm armor piercing projectile. Materials \& Design. 63: 427-438.

Kılıç, N., \& Ekici, B. (2013). Ballistic resistance of high hardness armor steels against 7.62mm armor piercing ammunition. Materials \& Design. 44: 35-48

Li, X. F., Li, H. B., Zhang, Q. B., Jiang, J. L., \& Zhao, J. (2018). Dynamic fragmentation of rock material: Characteristic size, fragment distribution and pulverization law. Engineering Fracture Mechanics. 199: 739-759.

Lin, L., Fan, F., \& Zhi, X. D. (2013). Dynamic Constitutive Relation and Fracture Model of Q235A Steel. Applied Mechanics and Materials. 274: 463-466.

Liu, J., Fan, Q., Cai, H., \& Wang, F. (2015). Underlying mechanism of periodical adiabatic shear bands generated in Ti-6Al-4V target by projectile impact. Materials \& design. 87: 231-237.

Lundberg, P., Renström, R., \& Lundberg, B. (2000). Impact of metallic projectiles on ceramic targets: transition between interface defeat and penetration. International Journal of Impact Engineering. 24(3): 259-275.

Lynch, N. J., Bless, S. J., Cullis, I. G., \& Berry, D. (2006). The influence of confinement on the penetration of ceramic targets by KE projectiles at 1.8 and 2.6km/s. International Journal of Impact Engineering. 33(1-12): 390-401.

Madhu, V., Ramanjaneyulu, K., Balakrishna Bhat, T., \& Gupta, N. K. (2005). An experimental study of penetration resistance of ceramic armour subjected to projectile impact. International Journal of Impact Engineering. 32(1-4): 337-350.

Rosin P. (1933). The laws governing the fineness of powdered coal. J Inst Fuel(7): 29-36.

Rahbek, D. B., \& Johnsen, B. B. (2019). Fragmentation of an armour piercing projectile after impact on composite covered alumina tiles. International Journal of Impact Engineering. 133: 103332.

Rakvåg, K. G., Børvik, T., Westermann, I., \& Hopperstad, O. S. (2013). An experimental study on the deformation and fracture modes of steel projectiles during impact. Materials \& Design. 51: 242-256.

Rakvåg, K. G., Børvik, T., \& Hopperstad, O. S. (2014). A numerical study on the deformation and fracture modes of steel projectiles during Taylor bar impact tests. International Journal of Solids and Structures. 51(3-4): 808-821.

Savio, S. G., Ramanjaneyulu, K., Madhu, V., \& Bhat, T. B. (2011). An experimental study on ballistic performance of boron carbide tiles. International Journal of Impact Engineering. 38(7): 535-541.

Savio, S. G., Senthil, P., Singh, V., Ghoshal, P., Madhu, V., \& Gogia, A. K. (2015). An experimental study on the projectile defeat mechanism of hard steel projectile against boron carbide tiles. International Journal of Impact Engineering. 86: 157-166.

Savio, S. G., \& Madhu, V. (2017). Effect of Tile Thickness and Projectile Velocity on the Ballistic Performance of Boron Carbide Against 12.7 mm AP. Procedia Engineering. 173: 286-292.

Sukumar, G., Bhav Singh, B., Bhattacharjee, A., Siva Kumar, K., \& Gogia, A. K. (2013). Ballistic impact behaviour of $\beta$-CEZ Ti alloy against $7.62 \mathrm{~mm}$ armour piercing projectiles. International Journal of Impact Engineering. 54: 149-160.

Wang, Q., Chen, Z., \& Chen, Z. (2013). Design and characteristics of hybrid composite armor subjected to projectile impact. Materials \& Design. 46: 634-639.

Zaera, R., \& Sánchez-Gálvez, V. (1998). Analytical modelling of normal and oblique ballistic impact on ceramic/metal lightweight armours. International journal of impact engineering. 21(3): 133-148. 